\title{
Bactrocera oleae (Diptera: Tephritidae) organophosphate resistance alleles in Iberia: Recent expansion and variable frequencies
}

\author{
ISABEL PEREIRA-CASTRO ${ }^{1, *}$, BARBARA VAN ASCH $^{1, *}$, FERNANDO TRINDADE REI $^{2}$ \\ and Luís TEIXEIRA DA COSTA ${ }^{2}$
}

\begin{abstract}
${ }^{1}$ Instituto de Patologia e Imunologia Molecular da Universidade do Porto (IPATIMUP), Rua Dr. Roberto Frias, s/n, 4200-465 Porto, Portugal; e-mails: isabelpereiracastro@gmail.com; basch@ipatimup.pt

${ }^{2}$ Instituto de Ciências Agrárias e Ambientais Mediterrânicas (ICAAM), Universidade de Évora, Núcleo da Mitra, Apartado 94, 7002-774 Évora, Portugal; e-mails: frei@uevora.pt; luisteixeiracosta@gmail.com
\end{abstract}

Key words. Diptera, Tephritidae, organophosphate, resistance, Bactrocera oleae, acetylcholinesterase, genetics, olive, olive fly

\begin{abstract}
The olive fly, Bactrocera oleae (Rossi, 1790) (Diptera: Tephritidae), is the most important pest of olive trees globally, causing losses that, in the absence of control measures, can exceed $90 \%$ of the crop. In the Mediterranean basin, where the overwhelming majority of production is concentrated ( $\sim 98 \%)$, organophosphate insecticides (OPs) have been the main tool for B. oleae control for the last four decades, leading to the development of resistance to these compounds. Mutations of the Ace gene, which codes for acetylcholinesterase, the target enzyme of OPs and other insecticides, have been identified as the underlying cause, with studies reporting mid to very high frequencies of resistance alleles in several countries. Interestingly, no resistance alleles were detected in Portugal, at the Western end of the Mediterranean basin. As the original study was done almost a decade ago and did not include many samples, we decided to re-evaluate the situation, by analysing a larger number of individuals from multiple locations in Western and Southern Iberia (Portugal and Spain). In our present study, resistance-associated Ace alleles were found to have become widespread in both regions, but with highly varying frequencies. Together with the observed haplotype distributions, this finding is consistent with previous suggestions of a recent, selection-driven spread and has implications for the importance of Ace mutations in organophosphate resistance in the field as well as the importance of gene flow between Mediterranean populations of $B$. oleae.
\end{abstract}

\section{INTRODUCTION}

The olive fly, Bactrocera oleae (Rossi, 1790) (Diptera: Tephritidae), is the most important pest of olive trees, causing losses estimated to average some $15 \%$ of production - or more than a billion US dollars per annum. However, in the absence of control measures, losses can be much higher, in some cases exceeding $90 \%$ of the crop (Montiel Bueno \& Jones, 2002; Skouras et al., 2007). In the Mediterranean basin, where the overwhelming majority of the world's production is concentrated $(\sim 98 \%)$, chemical insecticides, particularly organophosphates (OPs), have been the main tool for $B$. oleae control for the last four decades (Tsakas \& Krimbas, 1970; Vontas et al., 2001). As with other widespread pests, such usage would be expected to lead to the development of resistance to these compounds (Feyereisen, 1995), and indeed this was observed, both in the laboratory and on the field, more than a decade ago (Vontas et al., 2001).

Biochemical and molecular analysis of acteylcholinesterase (AChE), the target enzyme of OPs and other insecticides, and the Ace gene, which encodes it, has led to the identification of mutations in that gene as the underlying cause of OP resistance in olive fly (Vontas et al., 2001, 2002; Kakani et al., 2008). Two of these alterations (I214V and G488S) affect amino-acids close to the active site of the enzyme, and are thought to cause topological alterations that decrease the effectiveness of the action of OPs (Mutero et al., 1994; Walsh et al., 2001; Vontas et al., 2002). Interestingly, identical mutations were found in laboratory-developed OP-resistant Oriental fruit fly, Bactrocera dorsalis (Hendel), and $\mathrm{I} 214 \mathrm{~V}$ is equivalent to the I199V mutation found earlier in field resistant strains of Drosophila melanogaster (Meigen) (Mutero et al., 1994; Hsu et al., 2006), providing support for the notion of parallel evolution of resistance-associated mutations (ffrenchConstant et al., 2004). Both Ace I214V and G488S substitutions were found at high or very high frequencies in natural B. oleae populations in Greece, Albania and Italy, and less frequently in populations in France, Spain and Turkey (Hawkes et al., 2005; Nardi et al., 2006; Baskurt et al., 2011). A third mutation of a completely different type was later discovered in natural $B$. oleae populations, also in the Ace gene, in association with high levels of OP resistance: a 9 bp-deletion causing the loss of three consecutive glutamine residues $(\Delta 3 \mathrm{Q})$ near the carboxyl-terminus of the protein (Kakani et al., 2008). This is thought to increase the efficiency of AChE GPI-anchoring, leading to a higher number of enzyme molecules in the synaptic cleft and consequently to a reduced sensitivity to OPs (Kakani et al., 2008, 2011). The $\triangle 3 \mathrm{Q}$ alteration has subsequently been found in natural $B$. oleae populations in several countries of the Mediterranean basin, albeit at lower frequen-

\footnotetext{
* These authors contributed equally to the study.
} 


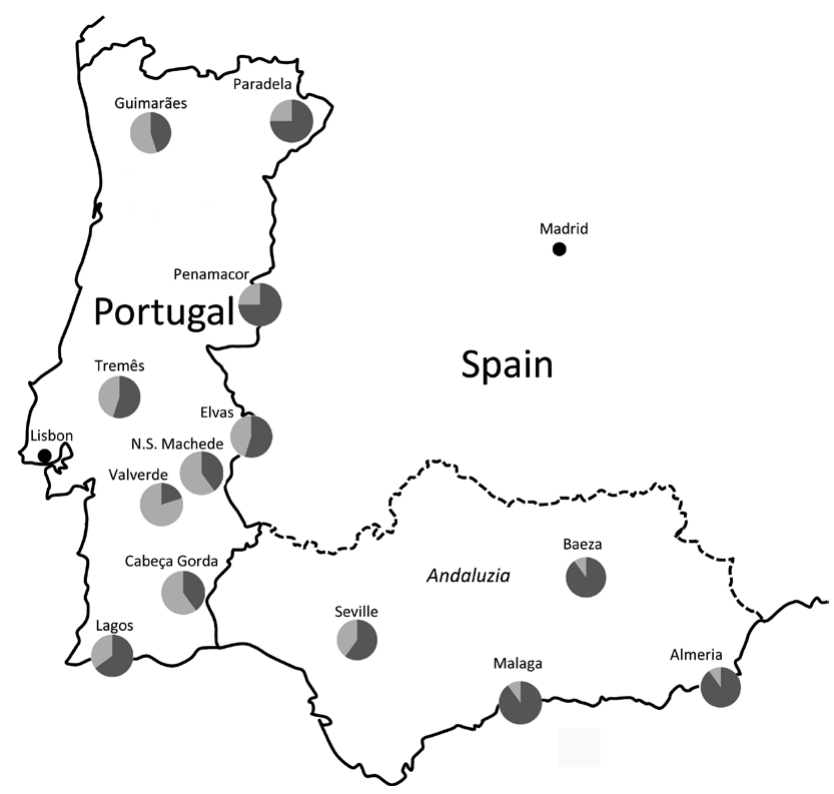

Fig. 1. Olive fly (Bactrocera oleae) collection sites in the Iberian Peninsula. Pie charts indicate the proportions of OP resistanceassociated (dark grey) and sensitivity-associated (light grey) alleles.

cies than I214V or G488S (Baskurt et al., 2011; Kakani et al., 2014).

Despite this widespread presence of OP-resistant olive flies in Europe, neither I214V and G488S (Nardi et al., 2006), nor, more recently, $\Delta 3 \mathrm{Q}$ (Kakani et al., 2014) were detected in Portugal, at the Western end of the Mediterranean basin. However, the sample size used for screening for I214V and G488S was small, and the flies tested were collected in 2001. Additionally, in Andalusia (southern Spain), the most intensive region of olive production (a third of the world's olives in fact), the frequencies of the I214V and G488S Ace substitutions were limited in natural populations assayed to about $30 \%$ in 2002 , in contrast to $80-90 \%$ and $60-90 \%$ for Greek and Italian populations, respectively (Hawkes et al., 2005; Nardi et al., 2006). Because in Greece the frequencies of resistance alleles had been found to change from $0-2.5 \%$ to $>90 \%$ in the period 1987-1999 (Hawkes et al., 2005; Margaritopoulos et al.,
2008), we hypothesized that a similar increase in OP-resistance alleles had occurred in the Iberian Peninsula since 2001. To test this hypothesis, $100+$ individual olive flies collected from thirteen locations in Portugal and Spain (Andalusia) were screened for the I214V, G88S and $\triangle 3 \mathrm{Q}$ alterations in the Ace gene.

\section{MATERIAL AND METHODS}

\section{Olive fly samples}

Olive flies were collected at or near 13 different localities, of which nine were in Portugal and four in Andalusia, Spain (Fig. 1, Table 1). At most collection sites, olives were picked and stored in plastic bags, with emerging larvae, pupae and adults being collected periodically, whereas at others, McPhail traps baited with a $5 \%$ solution of diammonium hydrogen phosphate (Sigma-Aldrich, Sintra, Portugal) were placed in olive groves for periods of 1-2 weeks and inspected every 1-2 days. Trapped adults were washed once in $70 \%$ ethanol before storage. All individuals were stored at $-20^{\circ} \mathrm{C}$ in $70 \%$ ethanol prior to DNA extraction.

\section{DNA extraction, amplification and sequencing}

Total DNA was extracted using a standard SDS/Proteinase K method. PCR amplifications (primers used in PCR amplification and sequencing are listed in Table 2) of the three fragments (Intron III/Exon IV, Exon VII and Exon X) of the Ace gene screened were performed in $25 \mu \mathrm{L}$ reactions containing $10 \mathrm{ng}$ of genomic DNA, $75 \mathrm{mM}$ Tris-HCl, $\mathrm{pH} 8.8,20 \mathrm{mM}\left(\mathrm{NH}_{4}\right)_{2} \mathrm{SO}_{4}, 0.01 \%$ (v/v) Tween 20 (Fermentas, Vilnius, Lithuania), $1.5 \mathrm{mM} \mathrm{MgCl}_{2}$ (Fermentas), $0.25 \mathrm{mM}$ of each deoxy-NTP (Fermentas), $175 \mathrm{ng}$ of each primer (Metabion International, Steinkirchen, Bavaria, Germany and Macrogen, Seoul, Republic of Korea) and 1.0 U of Taq DNA polymerase (Fermentas). The thermocycling protocol was: $95^{\circ} \mathrm{C}$ for $3 \mathrm{~min} ; 38-40$ cycles of $95^{\circ} \mathrm{C}$ for $30 \mathrm{~s}, 56^{\circ} \mathrm{C}$ for $45 \mathrm{~s}$ and $72^{\circ} \mathrm{C}$ for $30 \mathrm{~s}$; and $72^{\circ} \mathrm{C}$ for $3 \mathrm{~min}$. In general, primer pairs used for amplifications were: Bo12-009/BoAce 1040R, BoAce_1424F/BoAce_1519R and Bo12-023/Bo14-056, and sequencing reactions were performed with primers Bo12-027, BoAce 1519R and Bo14-057 (Fig. 2). For the I214V screen, amplification from a few samples was performed using twice the concentrations of Taq, dNTPs and $\mathrm{MgCl}_{2}$ in the PCR mixture and primers BoAce_518F/BoAce_1040R or Boace3F/Boace3R (Fig. 2). In the latter case, Boace $3 R$ was also used for sequencing. To determine the sequences of intron III and intron IV, PCR was performed with the primer pair Bo12-009/Bo12-010 and the duration of the extension step increased to $1 \mathrm{~min}$ and $15 \mathrm{~s}$. Sequencing was

TABLE 1. Distributions of the I214V and G488S Bactrocera oleae Ace gene substitutions at the 13 locations sampled. ${ }^{1} \mathrm{~S}-\mathrm{OP}-$ sensitive alleles (coding for 214I and 488G); R - OP-resistant alleles (coding for 214V and 488S). *Also screened for $\Delta 3 \mathrm{Q}$.

\begin{tabular}{|c|c|c|c|c|c|c|}
\hline \multirow{2}{*}{ Collection site (nearest locality) } & \multirow{2}{*}{$\begin{array}{l}\text { Geographic } \\
\text { coordinates }\end{array}$} & \multirow{2}{*}{ Collection date } & \multicolumn{3}{|c|}{ Genotype } & \multirow{2}{*}{$\begin{array}{l}\mathrm{R} \text { allele } \\
\text { frequency }\end{array}$} \\
\hline & & & $\mathrm{SS} / \mathrm{SS}^{1}$ & $\mathrm{SR} / \mathrm{SR}^{1}$ & $\mathrm{RR} / \mathrm{RR}^{1}$ & \\
\hline Paradela* & $41.58 \mathrm{~N} ; 6.25 \mathrm{~W}$ & Oct 2012 & 0 & 5 & 5 & 0.75 \\
\hline Guimarães & $41.46 \mathrm{~N} ; 8.31 \mathrm{~W}$ & Dec 2011/Nov 2012 & 3 & 5 & 2 & 0.45 \\
\hline Penamacor* & $40.16 \mathrm{~N} ; 7.10 \mathrm{~W}$ & Jan 2013 & 1 & 3 & 6 & 0.75 \\
\hline Tremês & $39.36 \mathrm{~N} ; 8.75 \mathrm{~W}$ & Nov 2009 & 1 & 7 & 2 & 0.55 \\
\hline Elvas & $38.86 \mathrm{~N} ; 7.27 \mathrm{~W}$ & Jul 2009 & 2 & 5 & 3 & 0.55 \\
\hline Nossa Senhora de Machede & $38.58 \mathrm{~N} ; 7.78 \mathrm{~W}$ & Aug 2009 & 3 & 6 & 1 & 0.40 \\
\hline Valverde & $38.53 \mathrm{~N} ; 8.02 \mathrm{~W}$ & Aug 2009 & 6 & 4 & 0 & 0.20 \\
\hline Cabeça Gorda & $37.91 \mathrm{~N} ; 7.82 \mathrm{~W}$ & Sep 2009 & 3 & 6 & 1 & 0.40 \\
\hline Lagos* & $37.13 \mathrm{~N} ; 8.68 \mathrm{~W}$ & Dec 2012 & 1 & 5 & 4 & 0.65 \\
\hline Seville* & $37.27 \mathrm{~N} ; 5.50 \mathrm{~W}$ & Oct 2012 & 1 & 6 & 3 & 0.60 \\
\hline Malaga* & $36.73 \mathrm{~N} ; 4.71 \mathrm{~W}$ & Oct 2012 & 0 & 2 & 8 & 0.90 \\
\hline Baeza & $38.05 \mathrm{~N} ; 3.37 \mathrm{~W}$ & Aug 2009 & 0 & 2 & 8 & 0.90 \\
\hline Almeria* & $36.89 \mathrm{~N} ; 2.44 \mathrm{~W}$ & Oct 2012 & 0 & 2 & 8 & 0.90 \\
\hline
\end{tabular}




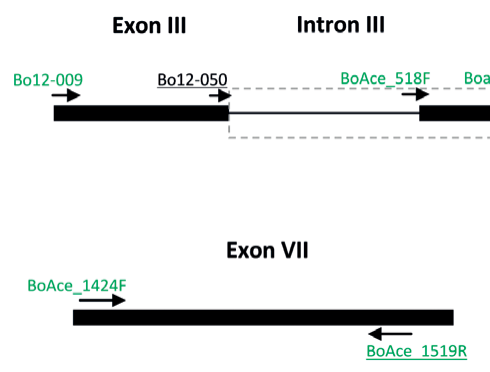

Exon IV

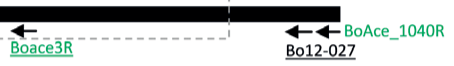

Bo12-027

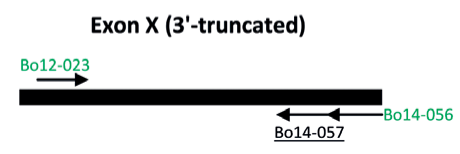

Fig. 2. Schematic representation of the segments of the Bactrocera oleae Ace gene analysed. Thick lines represent exons, the thin line an intron. Primers used for PCR are in green; those used for sequencing are underlined. The boxed region is shown in greater detail in Fig. 3. Elements in each segment are drawn to scale, but the representation for the smaller segments is twice enlarged relative to that of the bigger one.

done with the same two primers and BoAce 518F. Haplotype determinations in PCR products with more than one heterozygosity were made by sequencing with allele-specific primers (Bo12-051, Bo12-052, Bo14-118 or Bo14-147), or by allele-specific re-amplification of a $1: 100$ dilution of the original PCR product (Fig. 3). This was done using Bo12-009 and Bo12-051 or Bo14-125 (Figs 2 and 3) and a touch-down cycling protocol: $95^{\circ} \mathrm{C}$ for $1 \mathrm{~min}$; 14 cycles of $95^{\circ} \mathrm{C}$ for $30 \mathrm{~s}, \mathrm{~T}_{\text {hib }}$ for $30 \mathrm{~s}$ and $72^{\circ} \mathrm{C}$ for $30 \mathrm{~s}$; and $72^{\circ} \mathrm{C}$ for $1 \mathrm{~min}$, in which $\mathrm{T}_{\text {iib }}$ was $2 \times 68^{\circ} \mathrm{C}, 2 \times 66^{\circ} \mathrm{C}, 2 \times 64^{\circ} \mathrm{C}$, $2 \times 62^{\circ} \mathrm{C}, 2 \times 60^{\circ} \mathrm{C}$ and $4 \times 58^{\circ} \mathrm{C}$. Re-amplification products were sequenced with primers Bo12-050 and BoAce_518F. PCR products were used in sequencing reactions after purification with ExoI (Fermentas) and SAP (Fermentas). Part of the sequencing was outsourced to Macrogen Europe (Amsterdam, The Netherlands), and part was performed with the Big Dye Terminator Cycle Sequencing Kit (Applied Biosystems, Porto, Portugal) using the following cycling protocol: $96^{\circ} \mathrm{C}$ for $3 \mathrm{~min} ; 35$ cycles of $95^{\circ} \mathrm{C}$ for $15 \mathrm{~s}, 56^{\circ} \mathrm{C}$ for $15 \mathrm{~s}$ and $60^{\circ} \mathrm{C}$ for $2 \mathrm{~min}$; and $60^{\circ} \mathrm{C}$ for 5 $\mathrm{min}$. Sequencing reaction products were purified using Sephadex G-50 micro-spin columns (GE Healthcare, Carnaxide, Portugal) and sequenced using a ABI Prism 3130 XL sequence analyzer (Applied Biosystems). Sequence variants were detected by visually inspecting electropherograms using Chromas 1.45 (Techne-

TABLE 2. Sequences of PCR and sequencing primers used in this study.

\begin{tabular}{ll}
\hline Primer & Sequence (5'-3') \\
\hline BoAce_518F** & TACTCAATTTCACTTTCAGCACTC \\
BoAce_1040R** & CAACTCACCGACAATAGCG \\
BoAce_1424F** & CAGCTGGGTTGGTAATCC \\
BoAce_1519R** & TAGTGCACGGAAGCTCC \\
Bo12-009 & CTAGATATGAATATTTTCCCGG \\
Bo12-010 & ACCTTCGTCTCTGACATTTC \\
Boace3F* & GCTTACCCGTGCTTATTTGG \\
Boace3R* & AGCCAACGTATAGCCAATGC \\
Bo12-023 & TGAAGTCAAACCATCATCCG \\
Bo12-027 & GCATTACAATTGCAGTCGTTG \\
Bo12-050 & GCGCTAATGGCGGTGAG \\
Bo12-051 & CCCGATTGCATCATGCCC \\
Bo12-052 & CCCGATTGCATCATGCCA \\
Bo14-056 & TAGAAAAATGCATTTACTGACG \\
Bo14-057 & GACGGAATTTTTAAAACCAGTG \\
Bo14-118 & TCCTTTCATAATAAATTTCATTTC \\
Bo14-125 & CCCGATTGCATCATGCGC \\
Bo14-147 & TAGAACACAAGCTAACTAACTG \\
\hline
\end{tabular}

* From Hawkes et al. (2005). ** From Nardi et al. (2006). lysium Pty Ltd.), while editing and alignments were performed with CLC Main Workbench 6 (CLC Bio).

\section{RESULTS}

The primary goal of this study was to assess how the distribution of Ace OP-resistant alleles in the Western and Southern Iberian Peninsula had evolved since the first studies on the subject almost a decade ago (i.e. Hawkes et al., 2005; Nardi et al., 2006). We therefore focused on the two substitutions earlier described, I214V and G488S, involving screening a total of 130 Iberian flies for their presence. Searching for the $\Delta 3 \mathrm{Q}$ variant was restricted to the six locations most recently sampled (Table 1). To try to avoid potential local biases, and therefore obtain reasonable representations of the two regions studied, multiple, widely separated locations were sampled (Fig. 1). More sites were selected from Portugal, both because of the absence of resistance alleles during sampling in 2001 (Nardi et al., 2006) and because preliminary data suggested higher heterogeneity in populations from this region.

In terms of the resistance genotypes detected from our surveying regime, both $\mathrm{I} 214 \mathrm{~V}$ and G488S were found at medium to high frequencies in all locations, demonstrating they are now widespread, even in Portugal (Table 1). Interestingly, their frequencies vary widely, from $90 \%$ at various locations in Andalusia, to as low as $20 \%$ in Valverde, in the neighboring Portuguese region of Alentejo. In contrast, no alleles carrying the $\triangle 3 \mathrm{Q}$ variant were found in the 60 samples analysed, a result consistent with recently published data from the same regions (Kakani et al., 2014).

Data on haplotype frequencies and distributions at the Ace locus was also obtained. Unfortunately, the chromosomal distance between the two substitutions screened for (at least $13 \mathrm{~kb}$, and likely $>16 \mathrm{~kb}$; Kakani et al., 2013) and the lack of genomic sequence information made it unpractical to ascertain the gametic phase for all individuals. Nevertheless, it could be inferred for homozygous individuals in at least one of the two sites, representing 52\% of the Iberian flies tested (68/130). Interestingly, both variants had the same zygosity status in all cases, suggesting that, in Iberia at least, I214V and G488S are always found in the same chromosome. A more complete analysis was performed for haplotypes associated with OP-resistance and OP-sensitivity Ace alleles. To do this, the intronic sequences flanking the exon IV of the Ace gene, where the 
gtgagtgtggcttctaacaattttcaatttattagaacacaagctaactaactggarcacacactgcacatattgtaawattgccaactcattcatttccttcttatatttcctttyatamtmaatttcatttcaaatttogactttcagCA CTCCAATAAAGCTGACACTGATCATTTGATACACAACGGAAATCCGCAGAATATCACAAATGGCTTACCCGTGCTYYATTTGGATTTACGGKGGTGGCTTCATGACCGGCACTGC CACACTGGAT $\stackrel{*}{*}$ TATACAATGCGGACATTATGTCGGCTGTGGGTAATGTCATTGTGGCTTCGTTTCAATATCGTGTGGGCGCTTTTGGTTTCCTGCACCTGTCACCCGCTATGCCG GGCTACGAGGAGGAGGCACCCGGCAATGTGGGȘTTGTGGGATCAGGCMTTGGCTATACGTTGGCTGAAAACGAATGCTCACGCTTTCGGCGGTAATCCCGAGTGGATGACA CTTTTTGGTGAATCGGCTGGTTCGAGTTCGGTGAATGYGCAACTTGTGTCGCCAGTGACGGCGgGTTTGGTGAARCGKGGGCATGATGCAATCGGGCACAATGAATGCG Bo14-125/12-051/2

Fig. 3. Details of the sequence analysis of the Ace gene segment of Bactrocera oleae encompassing intron III and exon IV. Sequence variants (shaded) are labeled as follows: previously described - underlined; affecting protein sequence - bold; OP-resistance associated - marked with an asterisk. Primers indicated were used for allele-specific PCR or allele-specific sequencing. Bo12-051 and Bo12-052 differ in the last base, whereas Bo14-125 differs from Bo12-051 in having a sequence mismatch in the penultimate base.

I214V substitution is located, were obtained. Preliminary experiments had shown intron III to be polymorphic, and therefore the screen for $\mathrm{I} 214 \mathrm{~V}$ was designed to include amplification and sequencing of that intron as well (Fig. 2). Individual allele sequences were obtained for 116 of the Iberian samples, yielding a total of nine haplotypes (GenBank accession numbers KM204136-KM204145) defined by 15 sequence variants (Table 3 and Fig. 3). A stark contrast was found between chromosomes carrying OP-sensitive Ace alleles, 90\% of which had Hap01, and those with OP-resistant Ace alleles, that in $>99 \%$ of the cases (146/147) had Hap02, suggesting that virtually every case of olive fly OP-resistance in Iberia can be traced to the same genetic origin (Table 3). Of special interest was the finding that, though nine of the variants other than that causing $1214 \mathrm{~V}$ were either intronic or silent, one causes an Alanine to Valine substitution at residue 298. Because this residue is conserved in all the homologous fly proteins in a dataset including species from five different families (Table 4) and no other alteration was detected in this particular sample, the possibility that A298V represents a novel Ace mutation with functional consequences cannot be ruled out.

\section{DISCUSSION AND CONCLUSIONS}

As seen from the present results, it may firstly be accepted that a major alteration in the distribution of OP-associated Ace alleles has occurred in Iberia during the past decade. Indeed, the data show that average frequencies for both $\mathrm{I} 214 \mathrm{~V}$ and G488S have reached $>50 \%$ in Portugal and $>80 \%$ in Andalusia, in contrast with the previously reported values of zero and 33\%, respectively (Hawkes et al., 2005; Nardi et al., 2006). Even considering that those values were estimated from smaller sample sets, such alterations clearly reflect profound changes in the genetic make-up of populations, and cannot be ascribed simply to geographic variation and sampling effects. For example, although substantial frequency differences were found in Portugal, OP-resistant alleles were detected at every location sampled from, and in Paradela, closest to the site sampled by Nardi et al., in 2001 (Nardi et al., 2006), their frequency reached $75 \%$, the highest in the country.

Did these alleles arise in Iberia, or were they imported? The fact that the substitutions involved are identical and (with a single exception) occur in the same haplotypic background where they were found in other geographical locations points to the latter explanation, yet is not conclusive by itself since identical (or equivalent) Ace substitutions have been shown to arise independently, even in different species (Fournier, 2005; Hsu et al., 2006; Nardi et al., 2006). However, if the OP-resistant Ace alleles observed were of local origin, at least some individuals homozygous at the 214 position and heterozygous at 488 , or vice versa, would be expected to be found, as previously described in populations from several countries (Hawkes et al., 2005; Nardi et al., 2006; Baskurt et al., 2011). In

TABLE 3. Ace intron III / exon IV Bactrocera oleae haplotypes found in Iberia, and their absolute frequencies among 116 samples. Intron position numbering is that of the $149 \mathrm{bp}$ and $137 \mathrm{bp}$ variants.

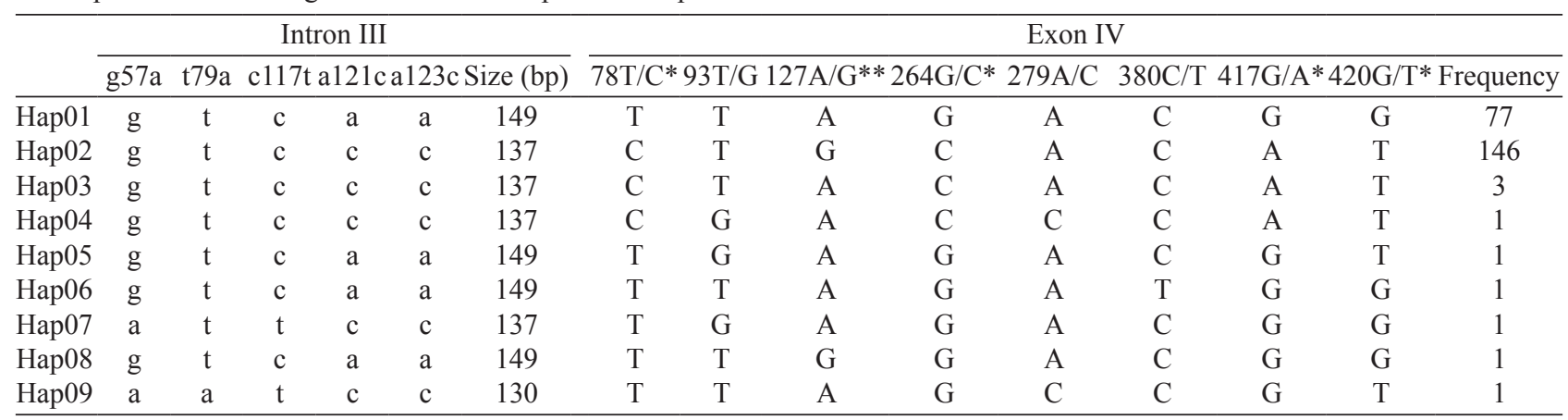

*Variants already described in Nardi et al. (2006). ${ }^{* *}$ Corresponds to $214 \mathrm{I} / \mathrm{V}$. 
TABLE 4. Fly species for which Ace sequences are available used for comparison with Bactrocera oleae in this study.

\begin{tabular}{|c|c|c|c|c|}
\hline Species & Family & Superfamily & GenBank (nt) & GenBank $(\mathrm{P})$ \\
\hline Bactrocera dorsalis & Tephritidae & Tephritoidea & JN112509 & AAO06900 \\
\hline Ceratitis capitata & Tephritidae & Tephritoidea & NM_001279434 & NP_001266363 \\
\hline Drosophila virilis & Drosophilidae & Ephydroidea & XM_002056133 & $X P \_002056169$ \\
\hline Drosophila willistoni & Drosophilidae & Ephydroidea & XM_002072251 & XP_002072287 \\
\hline Drosophila erecta & Drosophilidae & Ephydroidea & XM_001980267 & XP_001980303 \\
\hline Drosophila mojavensis & Drosophilidae & Ephydroidea & XM_001998863 & XP_001998899 \\
\hline Drosophila yakuba & Drosophilidae & Ephydroidea & XM_002097460 & XP_002097496 \\
\hline Drosophila melanogaster & Drosophilidae & Ephydroidea & X05893 & P07140 \\
\hline Drosophila sechellia & Drosophilidae & Ephydroidea & XM_002031326 & XP_002031362 \\
\hline Drosophila simulans & Drosophilidae & Ephydroidea & XM_002103562 & XP_002103598 \\
\hline Drosophila persimilis & Drosophilidae & Ephydroidea & XM_002013876 & XP_002013912 \\
\hline Drosophila grimshawi & Drosophilidae & Ephydroidea & XM_001990127 & XP_001990163 \\
\hline Drosophila pseudoobscura & Drosophilidae & Ephydroidea & XM_001358452 & XP_001358489 \\
\hline Drosophila ananassae & Drosophilidae & Ephydroidea & XM_001953033 & XP_001953068 \\
\hline Lucilia cuprina & Calliphoridae & Oestroidea & U88631.1 & AAC02779 \\
\hline Cochliomyia hominivorax & Calliphoridae & Oestroidea & FJ830868 & ACZ59082 \\
\hline Exorista sorbillans & Tachinidae & Oestroidea & HМ028669 & ADN37668 \\
\hline Haematobia irritans & Muscidae & Muscoidea & AY466160 & AAS45645 \\
\hline Musca domestica & Muscidae & Muscoidea & AJ310134 & CAC39209 \\
\hline Stomoxys calcitrans & Muscidae & Muscoidea & HM125963 & ADJ67805 \\
\hline
\end{tabular}

Turkey, for example, such genotypic discrepancies were detected in all populations tested, at an average frequency of $20 \%$ (Baskurt et al., 2011). The observation of complete concordance between the zygosities of I214V and G488S in Iberian samples therefore strongly suggests that their presence in Iberia is due to the introduction of flies with a chromosome already carrying both substitutions. Nevertheless, the occurrence of endogenously-generated identical substitutions cannot be excluded. Indeed, Hap03, from which almost all the resistance alleles derive (compare haplotypes Hap02 and Hap03 in Table 3) was also found in Iberia, albeit at a low frequency, viz. 3.5\% of OP-sensitive alleles. Furthermore, the single case where OP-resistance was found in the haplotype background usually associated with sensitivity alleles (Hap08, Table 3 ) might be an example of such a parallel process, as the alternative explanation would require a double recombination within a distance of less than $200 \mathrm{bp}$. Lastly, as mentioned above, the possibility that the A298V substitution found in one of the Portuguese samples alters sensitivity to OPs cannot be excluded. Indeed, not only is Alanine 298 conserved in all the fly species studied to date, but it is also very close to two residues with major roles in AChE protein function - Glu289 and Ser290, the latter a part of the catalytic triad.

Regardless of whether OP-resistance alleles have a regional origin or were imported, the data reported here has some bearing on whether the $\mathrm{I} 214 \mathrm{~V} / \mathrm{G} 488 \mathrm{~S}$ combination plays an important role in the field. This has been a controversial issue: although there is no dispute as to the importance of the two substitutions in OP-resistance under controlled laboratory conditions (Vontas et al., 2002; Hsu et al., 2006), and initial field data indicated that selection played a major role in their geographic dispersal and distribution (Hawkes et al., 2005; Nardi et al., 2006), later studies failed to detect correlations between their frequencies and either levels of OP resistance (Kakani et al., 2008) or insecticide treatment regime (Baskurt et al., 2011). Given the large number of farms involved, many of them small, obtaining reliable information on OP use at all locations analysed in the present study over a decade-long period would be extremely difficult. For this reason, the study was not designed to evaluate those correlations in Iberia and therefore, it does not provide biochemical data on resistance levels or clear proof of a selection-driven OP resistance spread. Even so, the rapid spread of resistanceassociated Ace alleles here reported, when contrasted with the observed differentiation between mitochondrial DNA sequences from Iberian and Italic populations (van Asch et al., 2012, Matallanas et al., 2013), seems to support that hypothesis. For example, in Andalusia, the world epicenter of olive production, and dominated by large, high yielding orchards, the frequencies of both the I214V and G488S Ace gene variants rose from values of about $30 \%$, much lower than those found in Italy or Greece, to $>80 \%$, on par with those countries, in a 7-10 year period. By contrast, in Portugal, with a much lower orchard density and a varied production structure that includes many small and traditional farms, spread of these particular variants has also occurred, but average frequencies have remained significantly lower and, perhaps more importantly, display marked diversity. An extreme example of this diversity was found in the vicinity of Évora (Portugal), as OP-resistance alleles appeared to be twice as common in Nossa Senhora de Machede than in Valverde, only about $15 \mathrm{~km}$ away. Interestingly, there is a correlation between this difference and insecticide use: though in both cases collection took place in untreated groves, the former is a 1.0 ha plot surrounded by many treated olive farms, including an intensive orchard about $1 \mathrm{~km}$ away, whereas in Valverde, the olive trees are located within an area of "montado", a 
semi-wild landscape dominated by holm oak and cork oak, and eucalyptus plantations. More generally, it is tempting to speculate that the heterogeneity in the frequencies of OP-resistant Ace alleles observed in Portugal results from different local selective pressures that contemporary gene flow has not yet masked, mainly because introduction is so recent. Hence, it is perhaps not a coincidence that the lowest frequencies of OP-resistance alleles in Andalusia were found in Seville, the closest sampled population to Portugal itself.

Finally, these results provide insights concerning the timeframe for agriculturally harmful gene-flow among Mediterranean populations of the olive fly. Indeed, they show that, despite evidence suggesting there is marked differentiation and relatively restricted genetic exchange among populations in the region (Augustinos et al., 2005; Nardi et al., 2005, 2010; Zygouridis et al., 2009; van Asch et al., 2012), genetically-based threats can disperse throughout the Mediterranean basin in less than twenty years. This highlights the need to reinforce programmes aimed at genetically characterizing olive fly populations and monitoring their evolution over time, with particular emphasis on insecticide resistance.

ACKNOWLEDGEMENTS. The authors thank M. de Jesus Vicente (from Paradela) and R. Ramalho for their help in collecting olive fly samples, and H.D. Loxdale for his helpful editorial comments on the manuscript. Support for this work was provided by Portuguese national funds through the Foundation for Science and Technology under the Strategic Project PEst-C/AGR/ UI0115/2011 and project ALENT-07-0324-FEDER-001747, as well as by FEDER funds through the latter project and Operational Programme for Competitiveness Factors - COMPETE. BA and LTC were funded by FCT grants SFRH/BPD/73108/2010 and Ciência2008-ICAAM, respectively. Additional funding was provided by L. Teixeira da Costa, to overcome arbitrary limitations imposed by the Portuguese Finance Minister in April 2013. The funding agency had no influence on study design, content or writing of the paper, for which the authors are solely responsible.

\section{REFERENCES}

Augustinos A.A., Mamuris Z., Stratikopoulos E.E., D’Amelio S., Zacharopoulou A. \& Mathiopoulos K.D. 2005: Microsatellite analysis of olive fly populations in the Mediterranean indicates a westward expansion of the species. - Genetica 125: 231-241.

Baskurt S.I., Dogac E., Taskin V. \& Taskin B.I. 2011: Frequencies of organophosphate resistance-associated mutations in the acetylcholinesterase gene of field collected olive fly ( $\mathrm{Bac}$ trocera oleae) populations under different insecticide regimes. - Acta Biol. Hung. 62: 22-33.

FEYEREISEN R. 1995: Molecular biology of insecticide resistance. — Toxicol. Lett. 82/83: 83-90.

FFrench-Constant R.H., Daborn P.J. \& Le Goff G. 2004: The genetics and genomics of insecticide resistance. - Trends Genet. 20: $163-170$.

FOURNIER D. 2005: Mutations of acetylcholinesterase which confer insecticide resistance in insect populations. - Chem. Biol. Interact. 157/158: 257-261.

Hawkes N.J., Janes R.W., Hemingway J. \& Vontas J. 2005: Detection of resistance-associated point mutations of organophosphate-insensitive acetylcholinesterase in the olive fruit fly, Bactrocera oleae (Gmelin). - Pestic. Biochem. Phys. 81: 154-163.

Hsu J.C., Haymer D.S., Wu W.J. \& Feng H.T. 2006: Mutations in the acetylcholinesterase gene of Bactrocera dorsalis associated with resistance to organophosphorus insecticides. - Insect Biochem. Mol. Biol. 36: 396-402.

Kakani E.G., Ioannides I.M., Margaritopoulos J.T., Seraphides N.A., Skouras P.J., Tsitsipis J.A. \& Mathiopoulos K.D. 2008: A small deletion in the olive fly acetylcholinesterase gene associated with high levels of organophosphate resistance. - Insect Biochem. Mol. Biol. 38: 781-787.

Kakani E.G., Bon S., Massoulie J. \& Mathiopoulos K.D. 2011: Altered GPI modification of insect AChE improves tolerance to organophosphate insecticides. - Insect Biochem. Mol. Biol. 41: $150-158$.

Kakani E.G., Trakala M., Drosopoulou E., Mavragani-Tsipidou P. \& Mathiopoulos K.D. 2013: Genomic structure, organization and localization of the acetylcholinesterase locus of the olive fruit fly, Bactrocera oleae. - Bull. Entomol. Res. 103: 36-47.

Kakani E.G., Sagri E., Omirou M., IoAnnides I.M. \& MathiopouLos K.D. 2014: Detection and geographical distribution of the organophosphate resistance-associated Delta3Q ace mutation in the olive fruit fly, Bactrocera oleae (Rossi). - Pest Manag. Sci. 70: 743-750

Margaritopoulos J.T., Skavdis G., Kalogiannis N., Nikou D., Morou E., Skouras P.J., Tsitsipis J.A. \& Vontas J. 2008: Efficacy of the pyrethroid alpha-cypermethrin against Bactrocera oleae populations from Greece, and improved diagnostic for an iAChE mutation. - Pest Manag. Sci. 64: 900-908.

Matallanas B., Lantero E., M'SaAd M., Callejas C. \& OchanDo M.D. 2013: Genetic polymorphism at the cytochrome oxidase I gene in mediterranean populations of Batrocera oleae (Diptera: Tephritidae). - J. Appl. Entomol. 137: 624-630.

Montiel Bueno A. \& Jones O. 2002: Alternative methods for controlling the olive fly, Bactrocera oleae, involving semiochemicals. - IOBC/WPRS Bull. 25(9): 147-156.

Mutero A., Pralavorio M., Bride J.M. \& Fournier D. 1994: Resistance-associated point mutations in insecticide-insensitive acetylcholinesterase. - PNAS 91: 5922-5926.

Nardi F., Carapelli A., Dallai R., Roderick G.K. \& Frati F. 2005: Population structure and colonization history of the olive fly, Bactrocera oleae (Diptera, Tephritidae). - Mol. Ecol. 14: 2729-2738.

Nardi F., Carapelli A., Vontas J.G., Dallai R., Roderick G.K. \& FRATI F. 2006: Geographical distribution and evolutionary history of organophosphate-resistant Ace alleles in the olive fly (Bactrocera oleae). - Insect Biochem. Mol. Biol. 36: 593-602.

Nardi F., Carapelli A., Boore J.L., Roderick G.K., Dallai R. \& Frati F. 2010: Domestication of olive fly through a multiregional host shift to cultivated olives: comparative dating using complete mitochondrial genomes. - Mol. Phyl. Evol. 57: 678-686.

Skouras P.J., Margaritopoulos J.T., Seraphides N.A., IoANNides I.M., KaKani E.G., Mathiopoulos K.D. \& Tsitsipis J.A. 2007: Organophosphate resistance in olive fruit fly, Bactrocera oleae, populations in Greece and Cyprus. - Pest Manag. Sci. 63: $42-48$.

Tsakas S. \& Krimbas C.B. 1970: The genetics of Dacus oleae. IV. Relation between adult esterase genotypes and survival to organophosphate insecticides. - Evolution 24: 807-815.

van Asch B., Pereira-Castro I., Rei F. \& da Costa L.T. 2012: Mitochondrial haplotypes reveal olive fly (Bactrocera oleae) 
population substructure in the Mediterranean. - Genetica 140: 181-187.

Vontas J.G., Cosmidis N., Loukas M., Tsakas S., Hejazi M.J., Ayoutanti A. \& Hemingway J. 2001: Altered acetylcholinesterase confers organophosphate resistance in the olive fruit fly Bactrocera oleae. - Pestic. Biochem. Physiol. 71: 124-132.

Vontas J.G., Hejazi M.J., Hawkes N.J., Cosmidis N., Loukas M., JANES R.W. \& HEMINGWAY J. 2002: Resistance-associated point mutations of organophosphate insensitive acetylcholinesterase, in the olive fruit fly Bactrocera oleae. - Insect Mol. Biol. 11: 329-336.
Walsh S.B., Dolden T.A., Moores G.D., Kristensen M., Lewis T., Devonshire A.L. \& Williamson M.S. 2001: Identification and characterization of mutations in housefly (Musca domestica) acetylcholinesterase involved in insecticide resistance. Biochem. J. 359: 175-181.

Zygouridis N.E., Augustinos A.A., Zalom F.G. \& Mathiopoulos K.D. 2009: Analysis of olive fly invasion in California based on microsatellite markers. - Heredity 102: 402-412.

Received July 30, 2014; revised and accepted September 9, 2014 Prepublished online December 1, 2014 